\title{
Keeping Knowledge Secret in Edo-Period Japan ${ }^{1}$
}

(1600-1868)

\author{
Peter Kornicki
}

\begin{abstract}
Why were certain kinds of knowledge kept secret during the Edo period and what impact did secretive practices have on the relationship between manuscript and print? In this article these questions are explored through a close examination of selected manuscripts in various genres, including medicine, etiquette, flower arrangement, and poetry. From this it becomes clear that some knowledge leaked out into the world of print, either by accident or by design, and that in other cases secrecy was more effectively maintained. But even the appearance of printed books did not necessarily undermine manuscript transmission of knowledge, for person-to-person transmission via oral teaching as well access to manuscript embodiments of knowledge remained standard through the period in most knowledge traditions.
\end{abstract}

\section{Introduction}

In I945, young Louis Levy, A lieutenant in the Intelligence Corps of the British Army, was in the thick of the action in Burma. The Burma Campaign, often referred to as the "forgotten war", had involved terrible hardships for all the combatants, many of whom succumbed to the climate, the jungle or the many diseases it harboured. Levy had survived all this, but he was not a combatant in the normal sense: he fought the enemy with dictionaries. He had been trained at the School of Oriental and African Studies (SOAS) in London to translate Japanese military documents that were of intelligence value. In July 1945, just six weeks from the end of the war (though nobody had any idea that the end was so close), he secured an intelligence coup. He recognised that one of the documents brought to his attention was a detailed plan for the Japanese break-out across the

1. This is a text version of the lecture I was invited to give at the meeting of the Society for Textual Scholarship in Philadelphia on 21 March 2020, which was cancelled as a result of the COVID-19 pandemic. 
Sittang river in southern Burma, so he pulled forward his typewriter and began to type out a translation. ${ }^{2}$

What has this story to do with manuscript studies? After all, the result was a typed translation which he handed over to his superiors. The original, however, was not typed. It was a duplicated manuscript, as was common in the Japanese armed forces throughout the war, and it was because Levy had been trained at SOAS to read handwritten Japanese that he was able to translate the document smoothly into English. This raises an obvious question: why were battle plans circulated in the form of manuscripts by the Japanese armed forces? The answer lies in the difference between alphabetic and non-alphabetic scripts. Although typewriters for writing Japanese and Chinese did exist, they needed to have at least 3,000 pieces of type. The typist faced several trays each containing a large number of characters and had to select the one needed from the right tray. This was, of course, a much slower process than typewriting any alphabetic language, but in addition the whole machine was much bulkier and heavier than a standard typewriter as used in Europe or North America in the 1940s. Consequently, while the Allied armies in the field used typewriters and deployed duplicating machines to provide multiple copies, Japanese armies in the field relied upon handwriting and used a similar duplicating technology to make multiple copies of a manuscript text. ${ }^{3}$ Thus, manuscripts had a much longer public life in Japan than they had in the West. In the Edo period (1600-1868), which is the subject of this essay, manuscripts were similarly widespread even though the spread of commercial printing had made the printed book a commonplace commodity in the early decades of the seventeenth century.

Before turning to the use of manuscripts to keep knowledge secret in the Edo period, we need to keep in mind some aspects of the ecology of writing in Japan. Like other societies in East Asia except China, writing in Japan involved choices: which language to write in (literary Chinese or Japanese, or a mixture of the two) and which script to use (Chinese characters or the Japanese syllabaries, or a mixture of the two). Similarly, the production of texts also involved choices: manuscript, xylography (woodblock printing) or movable type. And these three technologies were closely connected, for xylography was in essence a means of reproducing handwriting and the pieces of wooden type used in movable-type printing in Japan reproduced

2. See Allen 1984, 506-09. Levy changed his surname to his mother's surname of Allen after the war.

3. On Japanese typewriters and manuscript reproduction, see KorNicki 2019, 272-84. 
individual handwritten characters. It was xylography that commercial publishers relied upon for most of the Edo period apart from the first thirty years, for it offered the flexibility of allowing illustrations and pronunciation glosses, both of which enhanced the reach and appeal of printed books. Since every xylographic book was printed with woodblocks which were carved from a handwritten original, it is entirely appropriate that Julie Nelson Davies and Linda Chance have described xylography as "manuscript in print" $(2016,90)$. For this reason, throughout the Edo period the borderline between manuscript and print was fuzzy and the world of print was dominated by reproduced handwriting.

\section{Secrecy in Japan}

Let us now turn to the main topic, keeping knowledge secret in the Edo period. At first sight, the notion of secrecy seems to sit uncomfortably with the notion of a "public library of information", a term which Beth Berry (2007) memorably coined to refer to the use of print in seventeenth-century Japan. As she emphasized, xylography was used throughout the Edo period to put knowledge into the public domain, and this included maps, guidebooks, lists of products, and a whole host of other publications which made worldly knowledge easily accessible. This also applied to classical Japanese texts which had hitherto been confined to the scribal culture of the court: they, too, were put in the public domain for the first time in the early 17 th century. There is no denying, therefore, that a lot of texts and much knowledge reached, for the first time, what can now be described as a "public".

Yet, a great deal was not published and thus was held back from the public, as we will see. That prompts the question why there was a need for secrecy and what the origins of secrecy were in Japan. The development of traditions of secrecy in knowledge systems in Japan is usually assigned to the second half of the Heian period, that is, the eleventh and twelfth centuries. It is usually linked with the transmission to Japan of esoteric schools of Buddhism which reserved certain texts, and the knowledge they contained, for exposure only to initiates. Transmission of this knowledge was strictly limited and was conducted both orally as well as in the form of manuscripts. ${ }^{4}$

At around the same time, similar traditions of secrecy came to be applied to poetry composition. There may be a link between poetry com-

4. See TeEuwen 2006, 1-34, as well as the articles collected under title "Étude de l'époque d'Edo à travers les transmissions secretes (hiden) d'un art ou d'une pensée", edited by Anon. 2006. 
position and esoteric Buddhism that might explain this development, but no concrete evidence has yet been found. What needs to be remembered, rather, is that this shift in the handling of knowledge was mirrored by the dismemberment of the Japanese state and the growing privatization of land and power at the same time. The statist model of society, developed in Japan largely on the basis of Chinese practices, had postulated that the state was the ultimate owner of the land, but by the 11th century state lands had been parcelled off into private estates and the very offices of state had become the hereditary property of individual families, even including the professorships at the university.

Thus, the growth of secrecy is best seen, in my view, as another facet of the process of privatization in medieval Japan: powerful families grabbed land, power and knowledge and made them their own. It is for this reason that Allan Grapard $(1999,541)$ refers to changes in religious practices as the "privatisation of ritual activity".

At first, it was vernacular knowledge that mattered to the court, that of poetry composition. Let me emphasize the vernacular, for secret traditions barely developed in continental knowledge systems such as Confucianism and East Asian medicine, or even Buddhism, apart from the esoteric traditions mentioned above. Poetry was not the only vernacular knowledge system that was affected, for the same applied to vernacular medicine, the rituals of the tea ceremony, flower arrangement, military techniques, and many other areas. The process can be seen in Sakuteiki (On the making of gardens), a treatise on landscape gardening written in the eleventh century. By the late thirteenth century a colophon urging secrecy had been added to the manuscript tradition: the mention of secrecy was a new addition and was not present in older copies (SLAwson 1987, 50).

By the early seventeenth century, many of these secret knowledge traditions had been professionalized and turned into a system of financial support for an extended family over many generations. "Secret teachings were commodified and made ready for retail", as Maki Morinaga has put it $(2005,7)$. The conflicts that were involved can be clearly seen in a book on swordsmanship, the Heihō kadensho (Transmitted book of military techniques) by Yagyū Munenori (1571-1646), which was written in 1632:

What is to be written down momentarily in these three volumes is a piece of writing that does not go out of the ie [extended family]. However, it is not that the Way is to be hoarded up in secrecy. The purpose of keeping it secret is to let it be known. Were it unknown, the writing would be equal to null. May my descendants deliberate this point.

(Morinaga 2005, 35) 
Yagyū Munenori's remarks were addressed to his descendants and he envisaged a perpetual monopoly of knowledge. His family, it should be noted here, did not necessarily consist solely of his biological heirs, for nonagnatic adoption was practised in Japanese families in order to keep a lineage going. He was aware that not everything could be written down but also that, for the purposes of transmission, something had to be written down. Compendia of secret knowledge like this were transmitted vertically to descendants and horizontally to selected individuals. In this case Yagyū Munenori's descendants seem to have heeded his words, for very few copies of this work are extant and all are in very obscure libraries.

It is in circumstances such as these that a rhetoric of secrecy developed in Japan, expressed in words such as hiji, hiden, shinpi, and himitsu, all of which include the character that connotes secrecy and is read as $h i$ or $p i$ in Japanese. But secrecy was only part of the story, for these manuscript traditions involved both "monetary exchange and hereditary devolution of knowledge" (Morinaga 2005, 23). This tension between secrecy, transmission and financial gain can be seen in such disparate fields of vernacular knowledge as the theatrical arts, flower arrangement, the tea ceremony, landscape gardening, gunnery, and so on. In essence, if you, as an outsider, wished (and in some cases this is still true today) to acquire any one of these accomplishments, you had to choose which particular "school" of swordsmanship, gunnery or flower arrangement you wished to follow. Once you had joined, then you had access to oral and practical instruction and ultimately to the manuscript texts which embodied the "secret" knowledge. All this came at a financial cost, of course: the knowledge had not been privatised and professionalised for nothing.

If we were to construct a typology of "secrecy" in Edo-period Japan, what would be included? Secrecy meant any one or more of the following: out of sight of the authorities; out of sight of the common people; out of sight of rivals in the same line of business; protection of family traditions; protection of economic interests; protection of intellectual property; and monopoly of political information.

It was considerations of the kind mentioned above that governed the production of secret manuscripts in the Edo period. Secrecy did not mean absolute secrecy, as will be clear if we now consider some concrete examples. As we do so, let us keep three variables in mind: the nature of the knowledge and why it is being kept secret; the number of copies extant (if there are few, then we can consider the tradition to have been hermetic, but if there are many, then we can consider the texts to have been semipublished); and the relationship with the world of print — when did the 
knowledge embodied in the manuscript at least partially appear in print, if it ever has been printed?

First of all, let us take the example of waka poetry, the genre of 31-syllable verse which has been composed at least since the eight century. The development of secret traditions in the field of waka poetry as practised at court goes back to the twelfth and thirteenth centuries, when the families of famous poets such as Fujiwara no Teika (1162-1241) preserved the obiter dicta of their forebears but kept them secret from the crowds of poets who wanted to know them. By that time, as Miwa Masatane has argued, the universal aspirations of the Kokin wakash $\bar{u}$ (Collection of Poems Ancient and Modern), an anthology compiled in the tenth century and expressive of Japanese as opposed to Chinese tastes, had begun to give way to a Buddhist-influenced understanding of verse as an attempt to express inexpressible truths. Poetic families attempted to preserve their techniques and to maintain family continuity by keeping to themselves their knowledge about how those truths were to be expressed. In 1472, for example, the poet and monk Sōgi (1421-1502) heard lectures on the Kokin wakashu given by Tō Tsunenori, who flourished in the fifteenth century, in which the secret bits were written on separate bits of paper and passed to Sōgi and others qualified to receive them: they contained theories of poetry that emphasized esoteric connections with Shinto. From Soggi these secrets were transmitted to the Sanjōnishi family, and thence to later poets such as Hosokawa Yūsai (1534-1610) and Matsunaga Teitoku (1571-1654). As this example shows, oral transmission remained an important part of the process, but writing was also needed to preserve these secrets, sometimes in the form of coded writing (Mrwa 2017).

By the fifteenth century, therefore, and probably much earlier, there were already secret traditions for poetry composition: access to these naturally required pupillage. More importantly perhaps, the whole practice of poetry composition took place in circumscribed contexts. It is for this reason that the collections of long-lived families often include gigantic quantities of unpublished waka poetry, poetry manuals and similar material. One example is the Shiguretei Bunko in Kyoto, an aristocratic library that has been preserved intact for many hundreds of years but remained inaccessible until 2005. When finally opened to scholars, the collection was found to contain many poetry manuals and collections that are unique and had been hitherto unknown (see TANAKA 1997, 175-82). A less ancient case is that of the Tani family on the island of Shikoku, whose vast library, built up in the early eighteenth century, has been preserved intact. Most of their books were manuscripts, even in the case of texts that were already 


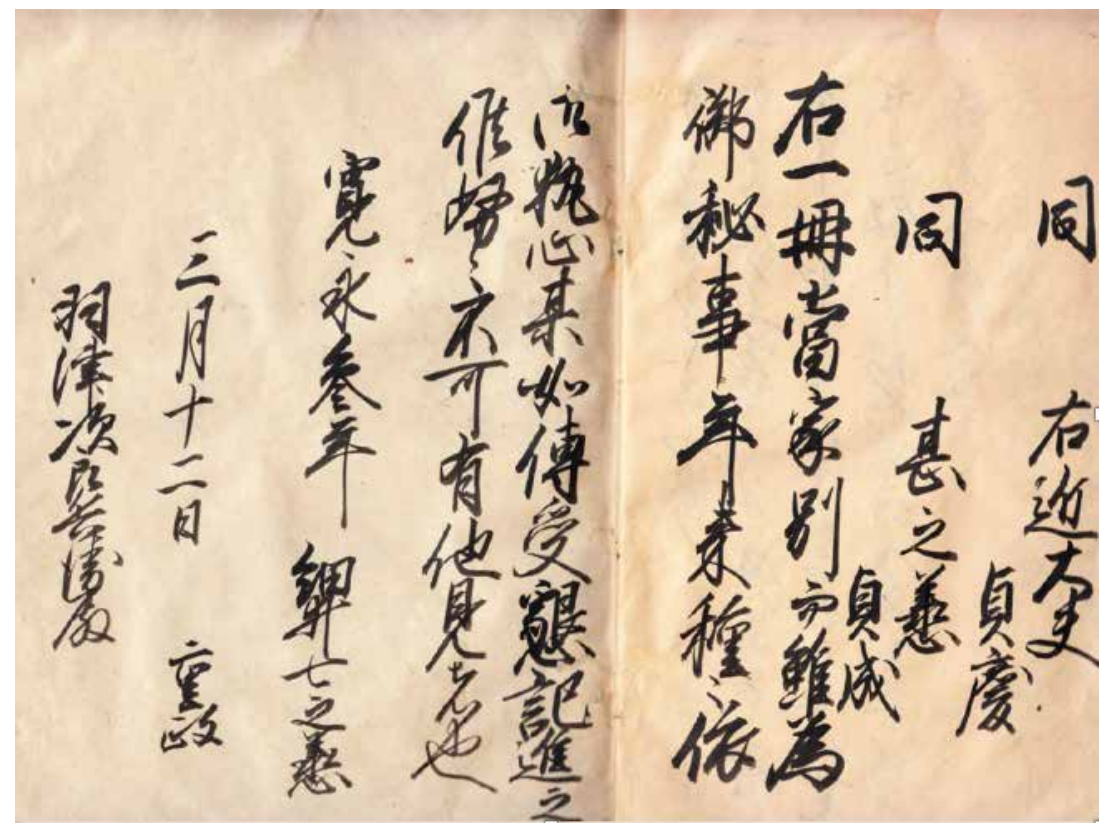

Figure 1. The etiquette of the Ogasawara School: secret manuscript of 1626 "not to be shown to others". Private Collection with Permission.

available in print, and many of them were labelled "secret books" in the family's catalogues. They included nine different versions of the secret traditions relating to the Kokin wakashu (Collection of Poems Ancient and Modern). We see here an overwhelming preference for manuscripts and a studied avoidance of commercially printed editions, as well as a desire to keep poetic practice out of the domain of commercial print. These family poetry collections were never printed until modern times and some have never been printed. ${ }^{5}$

By contrast with waka poetry manuals and anthologies, which remained more or less hermetic, manuals of etiquette, which were much in demand in the seventeenth century, failed to remain secret for long. Let us take, for example, a manual of etiquette with a colophon dated 1626, which tells readers how to sit up at table and how to arrange a meal tray tastefully. The colophon tells us that it is to be kept secret and not to be copied (see Fig. 1). In this case, however, some of the crucial information this gives about

5. The Tani collection has been little studied, but for a relatively recent catalogue, see Yoshizaki 1989. 


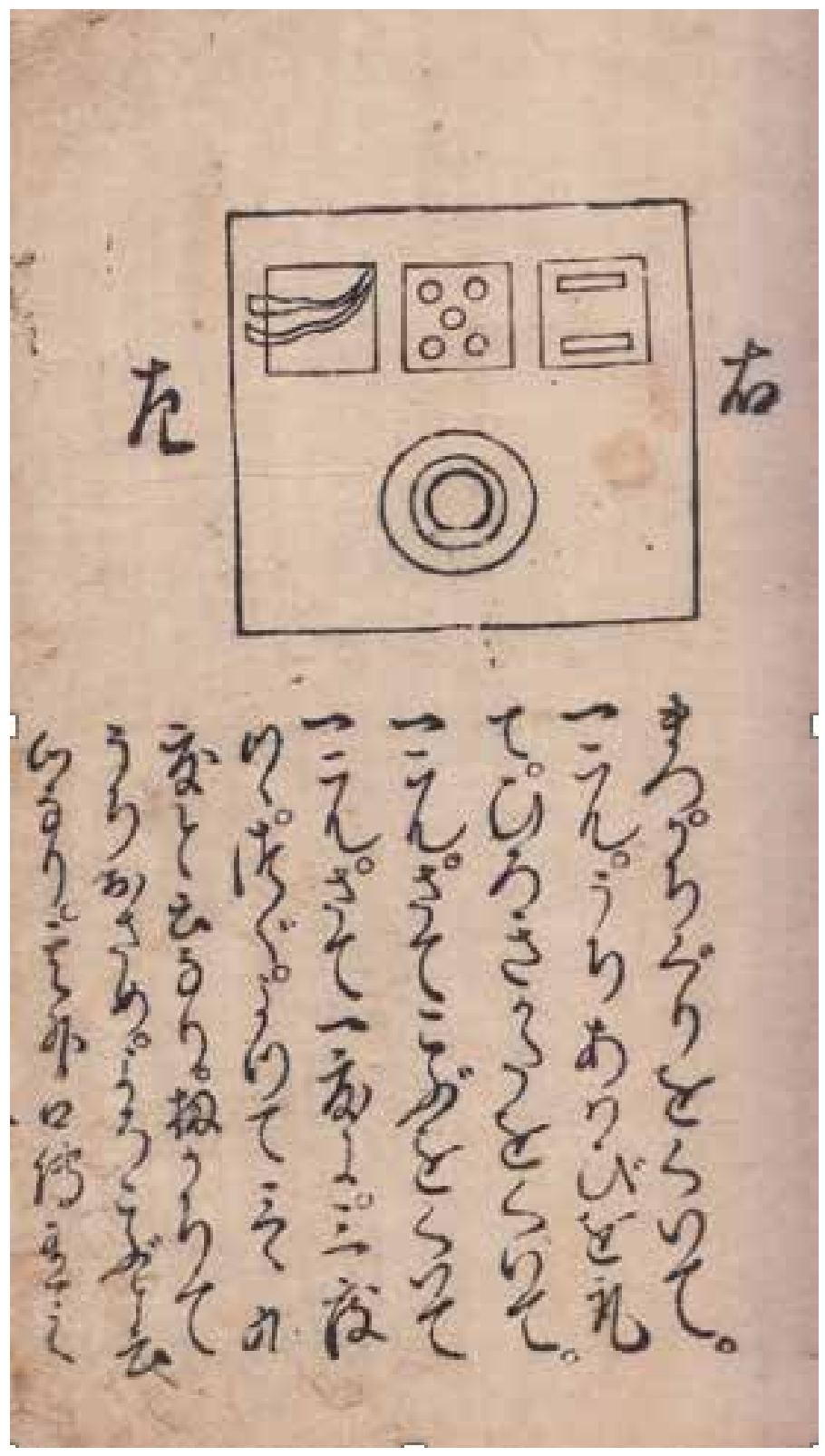

Figure 2. The etiquette of the Ogasawara School put into print in 1632: how to lay out a meal on a dining tray to be placed in front of a guest. Left and right are indicated to show that the soup bowl should be nearest the diner. Private Collection with Permission. 
how to sit up at table and how to arrange a meal tray leaked out. The earliest printed version of this text appeared in 1632, just six years later (see Fig. 2). The printed colophon informs readers that this is a book that had been kept secret by the Ogasawara family, who had a monopoly of knowledge concerning this particular school of etiquette. For them, printing their family secrets was probably not a total disaster. In order to get face to face instruction and oral guidance in matters not covered in the manuscripts or printed texts, and in order to get a licence become a teacher, you still needed to attend - and pay up, of course. In this case, there was a close connection between manuscripts and print, and manuscript production may even have been stimulated by print, for there are many manuscript copies in existence in addition to the various printed editions. In this way, privatised knowledge was partially allowed to slip into the public domain. Was that an accident, or did this in fact make the Ogasawara school of etiquette better known and actually increase the demand for instruction?

In the case of ikebana (flower arrangement), the existence of printed manuals shows that the keepers of the knowledge did not manage to keep it entirely out of the clutches of commercial printing. In the early seventeenth century, a flower arrangement book titled Sendensho was printed. At present, there are only two surviving manuscript copies of this text but ten printed copies from four or more different editions printed in the early seventeenth century. The colophon included in printed copies attests to its transmission as a secret text from 1445 by various stages up to 1536 , when it came into the hands of Sen no Ikenobō, the founder of the dominant Ikenobō school of flower arrangement, who himself left a number of his secret teachings in the form of manuscripts for his followers. How did the printers get hold of this hitherto secret text? Were printers colluding in the undermining of secret traditions, or, alternatively, were they being used by Ikenobo for the purposes of publicity? A few years ago, Cambridge University Library acquired a unique and beautifully illustrated sixteenthcentury manuscript of a treatise on flower arrangement. At the end there is a colophon attesting to its authenticity as the work of a flower arrangement master known by the name of Yuishinken. This is now the sole surviving record of a school of flower arrangement outside the mainstream, which is dominated to this day by the Ikenobō School. Flower arrangement was an important accomplishment in the sixteenth century and it still is; there was, and there still is, serious money to be made from it. What is important is that this is an authenticated and legitimate copy of an original that is now lost and that no further copies appear to have been made. Why not? Did Yuishinken's descendants preserve the secrecy so tightly that the 
knowledge was almost lost? Were they worried about loss of their secrets to the dominant Ikenobō school? Or is it possible that Ikenobō suppressed the knowledge of a rival school? It is at present impossible to answer these questions, but what is clear is that Yuishinken's techniques were recorded, copied and preserved.

Another area of knowledge in which there is a visible tension between print and manuscript is numismatics. Numismatics was a popular hobby in Edo-period Japan, partly because it was one of the few ways in which people could have access to the material culture of other societies and study it. From 1600 onwards, Japanese numismatists could collect European coins as well as Chinese, Korean and Vietnamese coins. There were a number of books printed to service this population of numismatists, and they contained rubbings of coins reproduced xylographically. Why, then, are there also so many manuscripts? This is clearly not a case of professionalized knowledge, and transmission was rarely if ever the aim. Rather, the object was the preservation and systematization of knowledge for private purposes: the knowledge was kept from rival collectors, but might be, and sometimes was, shared with colleagues.

One of the most interesting collections of Japanese numismatic manuscripts is that of the brilliant young Danish numismatist, William Sophus Bramsen (1850-1881), which is preserved in the National Library of Denmark. Bramsen went to Japan in 1875 as an employee of the Mitsubishi Mail Steam Ship Company and during his residence of five years he acquired a remarkable knowledge of Japanese as well as a fine collection of Japanese coins and numismatic books. Amongst his many manuscripts is one which bears the title, Honchō kōhakushi (Account of the yellow and white [gold and silver coins] of this country [Japan]), and which has a preface dated 1784. Bramsen's manuscript contains a note to say that it was copied in 1804 by a man called Hori Tokuei, who had borrowed a copy owned by a man named Hayashi Kizui. The original work was written by Toba Kisō (1739-1823) and there seem to be three copies of it extant in Japan, though I have not yet had a chance to examine them. Nevertheless, it is clear from this that this work did circulate to some extent among coin enthusiasts and generated further copies. ${ }^{6}$

6. See the National Museum of Denmark, Coin Cabinet, call no. XV t 90. The other copies, according to the Nihon Kotenseki Sōgō Mokuroku Dētabēsu (ID 496151), are in Tokyo University, Gakushūin University and the Iwase Bunko. 
Let us now turn to a different form of secrecy. In the early seventeenth century the prominent sinologist and government advisor Hayashi Razan (1583-1657) completed a translation of Tangyin Bishi (Legal cases compared), which had been compiled in 1211 by Gui Wanrong, an official of the Southern Song dynasty in China. It consists of a collection of anecdotes about the detection of crime and the wisdom of the detectives and judges who uncover the truth, and Gui's intention was to help his fellow magistrates to avoid making errors in their administration of justice. Hayashi Razan was the first person to mention this work in Japan, some 400 years after its composition in China. He completed his translation around the year 1616 under the title Tōin hiji genkai (Vernacular rendering of Tangyin Bishi), but why did he make one at all, given that, as probably the pre-eminent sinologist of his day, he was perfectly able to read it in the original literary Chinese? He made it, in fact, as a contribution to the political education of Tokugawa Yorinobu (1602-1671), who was the tenth son of Tokugawa Ieyasu, the founder of the Tokugawa shogunate, and who in 1619 became the first daimyo (hereditary lord) of the province of Kii.

Only two other copies of Toin hiji genkai are known, one from the collection of another daimyo, Matsudaira Tadafusa (1619-1700), and the other is known only from a recent auction catalogue and its current whereabouts are unknown. Many of Hayashi Razan's writings circulated only as manuscripts until after his death, when his sons arranged for their publication, but this particular work has never been published. Hayashi Razan was not averse to publication tout court, for during his lifetime he published several books of elementary instruction, so why did he restrict the circulation of Tōin hiji genkai? There was, of course, nothing inherently secret or private about his translation, but the key consideration was that it was made, possibly at the request of the shogun himself, for the edification of one of his sons. Given the high-status of the youth for whom the translation was intended, making it available at the same time to the vulgar masses in all likelihood seemed akin to lèse-majesté for Razan, who similarly kept out of the public eye several works he wrote for other high-status individuals. Of course, the other daimyo, Matsudaira Tadafusa, was a different matter: he was himself a scholar and knew Razan well enough to acquire copies of quite a few of his unpublished works. The third copy is a mystery: it cannot be Hayashi Razan's own copy, for that was lost in the fire that destroyed his library a few days before his death, so it is most likely a copy made by a follower either of Tokugawa Yorinobu or of Matsudaira Tadafusa.

Finally, let us turn to vernacular medicine. Chinese and Korean medical texts had been imported to Japan for centuries, and many of them were 
reprinted in Japan without any problem: they formed the basis of standard medical theory and practice in Japan. But vernacular treatments, which were not part of that general medical knowledge common to all parts of East Asia, were certainly not routinely made available in the form of print and there is a very large corpus of such manuscripts in Japan and in medical libraries around the world. Take, for example, a manuscript on smallpox lesions on the lips and tongue in the collection of the Wellcome Trust in London which bears the title Tōsō shinzetsuzu (Illustrations of lips and tongues with smallpox). This appears to be the holograph produced by the author, Ikeda Zuisen (1734-1816), and it contains carefully coloured illustrations. Ikeda Zuisen developed an interest in smallpox but had few opportunities to observe the symptoms until he was given the chance to attempt to stem an outbreak. As a result of his success, his fame spread and in 1797 he entered the service of the shogun as a specialist on smallpox. He wrote a number of works on smallpox, but none of them were ever published. There are only two other copies of this work known, one in Japan and the other in the library of UCLA. Why so few? The author may have felt constrained by his official position not to publish any of his findings, but his reluctance to publish was by no means uncommon among medical practitioners and was more likely due to his desire to protect his professional knowledge and the opportunity to earn a living from it. The latter consideration exercised a restraint on exercising too much secrecy, for, as Mark Teeuwen $(2006,26)$ has pointed out, "unknown secrets have no value"?

The notion that publication might undermine one's livelihood is very alien to us, but such considerations were in fact quite reasonable at the time and they certainly applied in the case of a much more famous doctor, Hanaoka Seishū (1760-1835), who deserves to be better known. In 1804 he conducted the first medical operation using a general anesthetic in the world. He was of course familiar with Chinese traditions of pharmacology, which recognised the anaesthetic properties of certain plants but which had no use for them in the absence of a tradition of surgical practice. But Seishū was also familiar with Western surgical techniques, of which he had acquired some knowledge from translated Dutch books. He had the brilliant idea in 1804 of marrying the two traditions: there was some urgency, for he had a female patient suffering from advanced breast cancer. He went ahead and operated: the operation was the first known use of a general anaesthetic in surgery anywhere in the world: it was to be 30 years before experiments in Georgia in the USA and in London led to the use of ether

7. See also Wellcome Collection, Japanese 94. 
and other substances in surgery for the same purpose. The operation was a success in the sense that his patient suffered no pain during the operation, but the operation in fact came too late and she only survived a few more months. Who today would not publicise such a discovery? Hanaoka Seishū did not do so. He kept a detailed record of the operation, with gruesome but accurate illustrations of the progress of the operation, and he became known as the doctor to go to if you needed a painless operation, for example for kidney stones. His many pupils, his many paying pupils that is, had access to this record and most of them made copies. Similarly, a detailed and illustrated record was kept of his many subsequent operations, and there is a particularly fine example in the library of the University of Pennsylvania. ${ }^{8}$ But it was not until 1851 , sixteen years after his death, that one of his pupils, Kamata Keishū (1794-1854), published an illustrated account of his most famous operation of 1804 and of subsequent operations; it was privately published rather being put on the commercial market, which makes it clear that the instinct for secrecy was still alive.

\section{Concluding remarks}

The maintenance of secrecy and the economic value of keeping knowledge secret are not, of course, strange practices from the East. Consider, for example, the invention of obstetric forceps by the Chamberlen family of Huguenot surgeons who fled from Paris to England. One or more members of the family, who were unusual in that they were male midwives, invented obstetric forceps in the seventeenth century and kept them as a family professional secret for at least 200 years. The forceps were hidden in a huge box when they went to the homes of their patients and they went so far as to blindfold their patients to preserve the secret. Similarly, when it came to the treatment of smallpox in the late eighteenth century, the notion of secrecy was not far away. Sir Walter Farquhar described vaccination as "the greatest discovery that has been made for many years" and said that Jenner could have earned $£ 10,000$ a year from it if he had kept it secret; and one Dr Woodville in Paris went out of his way to state that it was not his intention to keep his methods secret (Dunn 1999, 232-35 and BennetT 2020, 91 and 154-55). Publicity brought fame, but it also led to the loss of the income that a monopoly would have generated.

8. See Shunrinken kiranzu Gassuidō kiranzu: University of Pennsylvania Library, Codex 1766. 
Although such parallels can be found in the West, secrecy was much more widespread in Japan. Indeed, secrecy has in Japanese religion long been and still is a common practice. There is the secrecy of images, which are only exposed to view once every year, or five years or even 25 years; there is the secrecy of rituals that take place in closed settings; and there is the secrecy of doctrines that are only revealed to the initiated. There were parallels in the political world, too. The shoguns maintained their authority through secrecy and concealment, or what Timon Screech (2012, 167) has called the "iconography of absence": what is significant is what cannot be seen, like rulers who do not appear in public, whose images are not found on coins and who are present in palace audiences only behind screens. Secrecy had a cultural value and we can see it at work in the treatment of vernacular knowledge, as I have attempted to show.

To those who are familiar with the writings of Harold Love, David McKitterick, Henry Woudhuysen and others, the co-existence of manuscript and print will be a familiar topic. More recently, Peter Stallybrass (2008, 111-18) has argued that manuscript is a concept produced by printing, pointing out that no usages of the word "manuscript" are recorded in the Oxford English Dictionary before 1597. He has also drawn attention to the intermingling of print and manuscript in fifteenth-century indulgences which include blank spaces for names to be added by hand. In Japan, by contrast, shahon (manuscript) has a much longer history, and printed forms and similar non-book printing were non-existent until the nineteenth century.

On the other hand, in seventeenth-century Japan, xylographicallyprinted primers taught people how to do handwriting and they were thus partly responsible for the spread of literacy. In that sense, printed primers created the conditions for the huge growth of manuscript production in the Edo period: probably half of all the books produced between 1600 and 1868 in Japan were in fact manuscripts, although most studies of the history of the book in the Edo period focus on printed books. Japan was, it is not an exaggeration to say, largely a handwritten culture, whether in manuscript or xylographic print, and this remained true right up to the 1870 s for books and journals, and much later for other forms of writing.

Let me end with a note of self-criticism. Given the constraints of time, I only proposed, in the lecture underlying this article, to examine some of the reasons for the dynamic production of manuscript books in Edo-period Japan, and now, given the continued inaccessibility of libraries during the COVID-19 pandemic, I have been unable to make good this shortcoming. Therefore, there is no mention here of the impact of gender or geography 


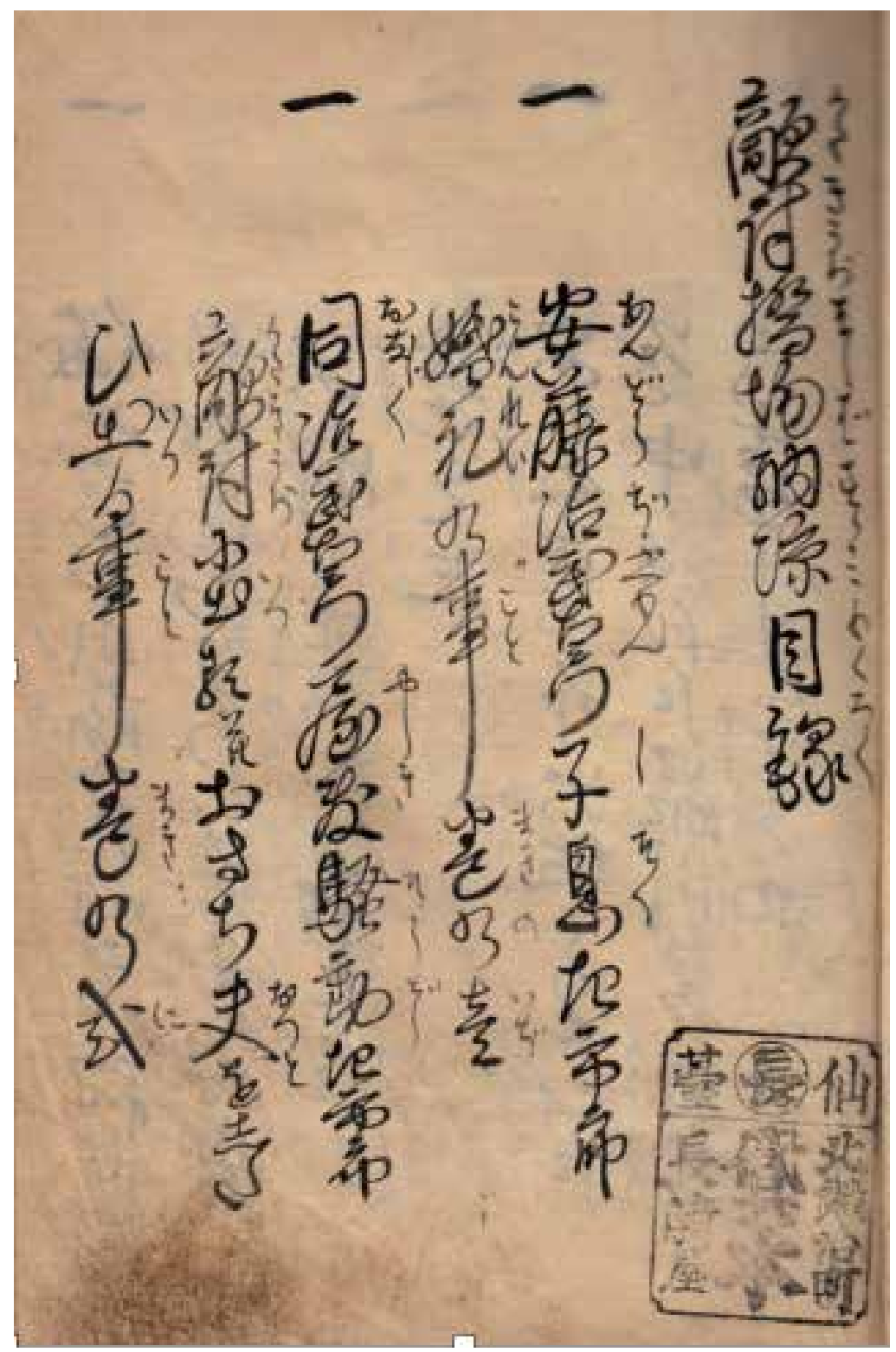

Figure 3. An account of a samurai vendetta in Sendai. Such "news" could only be circulated in manuscript owing to censorship regulations prohibiting the appearance of the names of living people in print. At the bottom right is an impression of the seal of a circulating library in Sendai. Private Collection with Permission. 
on the choice between print or manuscript for the production of books. This is regrettable for these were undoubtedly important variables. Most of the published writings by women during the Edo period turn out to have been written by women who took the tonsure, with the exception of a few poetry collections; as a result, the bulk of women's writing circulated in manuscript and has only recently been published and become easily accessible. Geography, in turn, was a factor in the sense that most printing and publishing was undertaken in the four big cities of Edo (Tokyo), Osaka, Kyoto and Nagoya, with the inevitable result that writings produced far away from these centres were more likely to circulate in manuscript, particularly if the contents were primarily of local interest, such as primers focusing on local place-names and industries. Secrecy was perhaps less of an issue in these cases, although the reluctance of women to publish is perhaps best explained as stemming from the desire not to make themselves "public". The situation is more complex in the case of manuscripts on political scandals: these tended to be produced in quantity and thus to constitute an instance of scribal publication, but they were sold "under the counter", for explicit bans were placed on the circulation of political manuscripts. It was imperative, therefore, that they were kept secret from the authorities (see Fig. 3). ${ }^{9}$

There is still much work to do on the balance and connections between manuscripts and print in Japan. Simon Franklin's recent work (2019) on the Russian graphosphere is valuably suggestive in this connection, but as yet few societies outside Europe have been closely studied from this perspective.

University of Cambridge

\section{Works Cited}

Allen, Louis. 1984. Burma: The Longest War. London: J. M. Dent \& Sons, Ltd.

Anon, ed. 2006. "Étude de l'époque d'Edo à travers les transmissions secretes (hidden) d'un art ou d'une pensée”. In Benkyô-kai. Sessions d'étude au CEEJA. 2001-2003. Aurillac: Presses Orientalistes de France.

Bennett, Michael. 2020. War Against Smallpox: Edward Jenner and the Global Spread of Vaccination. Cambridge: Cambridge University Press.

Berry, Mary Elizabeth. 2007. Japan in Print: Information and Nation in the Early Modern Period. Berkeley: University of California Press.

9. I have written at length on these manuscripts in KOR NICKI 2006. 
Chance, Linda H. and Julie Nelson Davies. 2016. "The Handwritten and the Printed: Issues of Format and Medium in Japanese Premodern Books". Manuscript Studies 1.1: 90-114.

Dunn, Peter M. 1999. "The Chamberlen Family (1560-1728) and Obstetric Forceps". Archives of Disease in Childhood: Fetal 83 Neonatal 81: 232-35.

Franklin, Simon. 2019. The Russian Graphosphere, 1450-1850. Cambridge: Cambridge University Press.

Grapard, Allan G. 1999. "Religious practices". In Shively and McCullough 1999, Volume 2, "Heian Japan".

Kornicki, Peter. 2006. "Manuscript, not Print: Scribal Culture in the Edo Period". Journal of Japanese Studies 32: 23-52.

2019. “Japan's Handwritten Culture: Confessions of a Print Addict”. Japan Forum 3: 272-84.

Miwa Masatane. 2017. Kagaku hidenshi no kenkyū. Tokyo: Kazama Shobō.

MorinagA, Maki Isaka. 2005. Secrecy in Japanese Arts: "Secret Transmission" as a Mode of Knowledge. New York: Palgrave Macmillan.

Screech, Timon. 2012. Obtaining Images: Art, Production and Display in Edo Japan. London: Reaktion Books.

Shively, Donald H. and William H. McCullough, eds. 1999. Cambridge History of Japan, Vol. 2, "Heian Japan”. Cambridge: Cambridge University Press.

Slawson, David A. 1987. Secret Teachings in the Art of Japanese Gardens. Tokyo: Kodansha International.

Stallybrass, Peter. 2008. "Printing and the Manuscript Revolution". In Explorations in Communication and History, edited by Barbie Zelizer, 111-18. London: Routledge.

TAnA Ka Noboru. 1997. Kohitsugire no kokubungakuteki kenkyū. Tokyo: Kazama Shobō. Teeuwen, Mark. 2006. "Japan's Culture of Secrecy from a Comparative Perspective". The Culture of Secrecy in Japanese Religion, edited by Bernhard Scheid and Mark Teeuwen, 1-34. London: Routledge.

Yosнizaki Hisashi, ed. 1989. Chinzan shomoku. Ise: Kōgakkan Daigaku Shintō Kenkyūsho. 